\section{MARTUN MARUETTA}

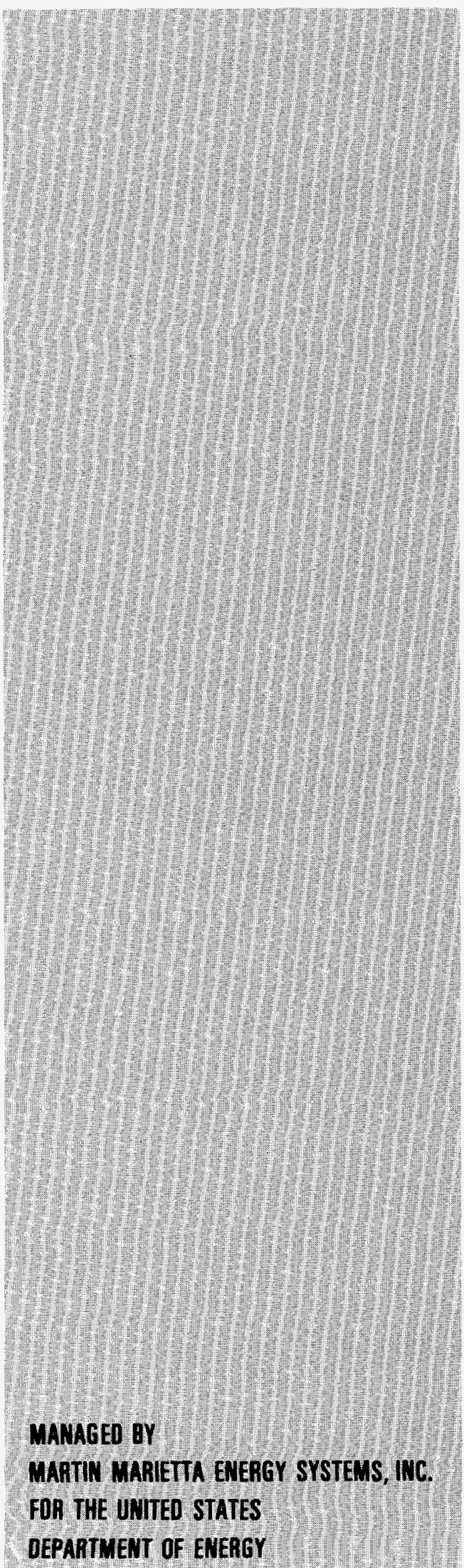

\section{PEIS DATA REPORT: UPGRADING THE Y-12 PLANT FOR LONG-TERM HEU STORAGE}

\author{
Prepared by \\ D. A. EVERITT \\ J.P. JOHNSON \\ J. K. PHILLIPS \\ J. D. SNIDER
}

Nuclear Materials Disposition Program Office Defense Programs

\section{FEBRUARY 1996}

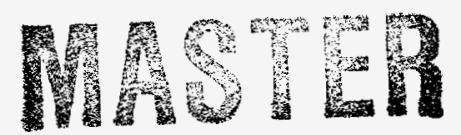

Prepared by the Oak Ridge Y-12 Plant

Oak Ridge, Tennessee 37831 managed by

Martin Marietta Energy Systems, Inc. for the

U.S. DEPARTMENT OF ENERGY under contract DE-AC05-84OR21400

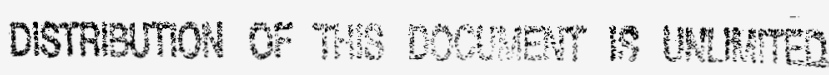




\title{
PEIS DATA REPORT: \\ UPGRADING THE Y-12 PLANT FOR LONG-TERM HEU STORAGE
}

\author{
Prepared by
}

D. A. EVERITT

J. P. JOHNSON

J. K. PHILLIPS

J. D. SNIDER

FEBRUARY 1996 


\section{DISCLAIMER}

Portions of this document may be illegible in electronic image products. Images are produced from the best available original document. 


\section{TABLE OF CONTENTS}

1.0 HEU Storage Missions and Assumptions ...................................................1

1.1 Disposition PEIS .............................................................................

1.2 Long-Term HEU Storage..............................................................1

1.3 HEU Materials Needing Long-Term Storage .......................................2

1.4 Long-Term HEU Storage Mission .........................................................2

1.5 Material Preparation for Long-Term Storage ........................................4

1.6 Other HEU-Related DP Missions.........................................................4

2.0 The Y-12 Plant..............................................................................................5

2.1 Y-12's Current Missions....................................................................

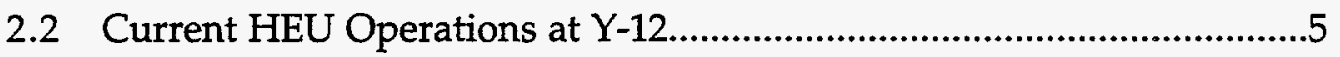

2.3 Interim HEU Storage at the Y-12 Plant .............................................6

2.4 Disposition PEIS Evaluations of the Y-12 Plant..................................6

3.0 The Y-12 Upgrade Alternative ...........................................................7

3.1 Long-Term HEU Storage at the Upgraded Y-12 Plant ...........................7

3.2 Other HEU Operations in the Upgraded Y-12 Plant............................9

3.3 Support Operations and Services.............................................................

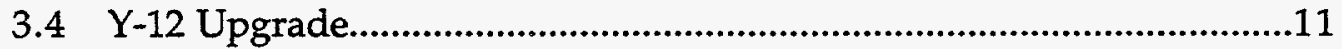

4.0 Upgrade Capital Projects..............................................................................13

4.1 Upgrade Capital Projects Required..................................................13

4.2 Natural Phenomena Upgrades .........................................................13

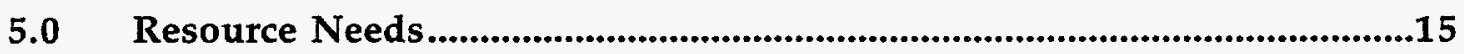

5.1 Materials/Resources Consumed for the Long-Term HEU Storage Mission ...................................................15

5.1.1 Utilities Consumed...............................................................15

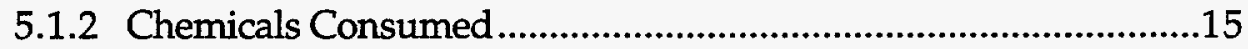

5.1.3 Radiological Materials Required .............................................16

5.2 Materials/Resources Consumed During Construction...........................16

6.0 Employment Needs ......................................................................................18

6.1 Employment Needs for the Long-Term HEU Storage Mission ..............18

6.2 Employment Needs During Construction..........................................19 
7.0 Wastes and Emissions

.20

7.1 Wastes and Emissions for the Long-Term HEU Storage Mission.

.20

7.1.1 Emissions

20

7.1.2 Solid and Liquid Waste

.20

7.1.2.1 Low-Level Waste (LLW)

.20

7.1.2.2 Hazardous Waste

.20

7.1.2.3 Nonhazardous Waste

.21

7.2 Wastes and Emissions Generated During Construction

.21

7.2.1 Emissions

.21

7.2.2 Solid and Liquid Wastes

.21

7.2.2.1 Hazardous Wastes.

.21

7.2.2.2 Nonhazardous Wastes

.21

ii 


\section{LIST OF TABLES}

Table

Title

Page

5.1.1. Utilities Consumed by the Long-Term Storage Mission ..............................15

5.1.2. Annual Chemicals Consumed by the Long-Term Storage Mission ...............16

5.2. Materials/Resources Consumed During Construction................................17

6.1. Employment for the Long-Term Upgrade Storage Mission..........................18

6.2. Number of Construction Employees Needed by Craft ..............................19

7.1. Annual Emissions for Long-Term Storage Mission ....................................20

7.2 Annual Wastes Generated for the Long-Term Storage Mission...................21

7.3. Emissions During a Peak Construction Year ..........................................22

7.4. Total Wastes Generated During Construction ............................................23 


\section{ACRONYM LIST}

\begin{tabular}{|c|c|}
\hline$A-E$ & Architect Engineer \\
\hline CDR & Conceptual Design Report \\
\hline Disposition PEIS & $\begin{array}{l}\text { "Programmatic Environmental Impact Statement for Long-Term } \\
\text { Storage and Disposition of Weapons-Usable Fissile Materials" }\end{array}$ \\
\hline DOE & Department of Energy \\
\hline $\mathrm{DP}$ & Defense Programs \\
\hline $\mathrm{EEO}$ & Equal Employment Opportunity \\
\hline ES\&H & Environmental Safety \& Health \\
\hline EUO & Enriched Uranium Operations \\
\hline FONSI & Finding of No Significant Impact \\
\hline FY & Fiscal Year \\
\hline HEU & Highly Enriched Uranium \\
\hline IAEA & International Atomic Energy Agency \\
\hline LLW & Low Level Waste \\
\hline MAA & Material Access Area \\
\hline NEPA & National Environmental Policy Act \\
\hline NMC\&A & Nuclear Materials Control and Accountability \\
\hline NPH & Natural Phenomena Hazard \\
\hline NWC & Nuclear Weapons Complex \\
\hline PA & Protected Area \\
\hline PEIS & Programmatic Environmental Impact Statement \\
\hline RCRA & Resource Conservation and Recovery Act \\
\hline ROD & Record of Decision \\
\hline SNM & Special Nuclear Material \\
\hline TEC & Total Estimated Cost \\
\hline $\mathrm{U}^{235}$ & Uranium 235 \\
\hline U.S. & United States \\
\hline
\end{tabular}




\subsection{HEU Storage Missions and Assumptions}

\subsection{Disposition PEIS}

The Department of Energy (DOE) is planning the future of weapons-capable fissile materials owned by the United States (U.S.). Under its Disposition Program, DOE is evaluating its options for: a) storage of fissile materials needed for specific national programs, and b) disposal of surplus fissile materials. In accordance with the National Environmental Policy Act (NEPA), DOE is preparing the "Programmatic Environmental Impact Statement (PEIS) for Long-Term Storage and Disposition of Weapons-Usable Fissile Materials" (Disposition PEIS).

One of the fissile materials covered by the Disposition Program is highly enriched uranium (HEU). Highly enriched uranium has been isotopically enriched so that its uranium $235\left(\mathrm{U}^{235}\right)$ content exceeds $20 \%$ of total uranium. A substantial quantity of U.S. owned HEU will be required for Defense Programs (DP) purposes, well into the next century. When not in use this material will be held in long-term storage facilities. Most remaining U.S.-owned HEU will be designated surplus and subsequently offered for disposition activities. The Disposition Program does not cover the storage and disposition of irradiated HEU materials.

\subsection{Long-Term HEU Storage}

The Disposition PEIS is evaluating various options for the long-term storage of HEU.

There are three types of long-term HEU storage alternatives being evaluated in the Disposition PEIS:

1. No Action. - Under this alternative, HEU will continue to be stored at some or all existing storage locations. No significant improvements will be made to these existing storage facilities.

2. Upgrade. - Under this alternative, HEU will continue to be stored at some or all existing storage locations. These storage facilities will be upgraded and storage operations would be improved to comply with all Federal, State and local environmental, safety and health $(E S \& H)$ regulatory requirements.

3. Collocated. - Under this alternative, a new long-term HEU storage facility will be built alongside a facility providing long-term storage for other fissile materials (e.g., Pu). Long-term highly enriched uranium storage at all existing storage facilities will be phased out. 


\subsection{HEU Materials Needing Long-Term Storage}

The Disposition Program plans to disposition a substantial quantity of surplus HEU prior to the year 2020. Under its long-term HEU storage mission the Disposition Program will store the remaining HEU required for various national missions, except for the HEU residing in the active nuclear weapons stockpile or possession of the U.S. Navy. The baseline quantity of HEU needed in long-term storage has been determined to be 6,000 cans and 8,500 drum positions.

Since the Disposition Program assumes that all surplus HEU will have been dispositioned prior to the year 2020, this long-term HEU storage mission does not consider any need for an HEU inventory held under International Atomic Energy Agency (IAEA) safeguards. Therefore, this report does not include any international inspection facilities.

Other HEU not considered in the long-term storage mission includes those HEU materials requiring remote storage and handling operations (e.g., irradiated uranium). All HEU contaminated with Pu in levels higher than background will be stored in the Disposition Program's long-term Pu storage facility. Irradiated HEU, which is contaminated with fission products, will be handled in various spent fuel programs outside the purview of the Disposition Program.

\subsection{Long-Term HEU Storage Mission}

The long-term HEU storage mission is assumed to begin in the year 2020, continuing for at least 50 years. The HEU material must be stored safely with no reasonable risk of release to the environment, endangerment to the public, or endangerment to workers. The HEU material must also be adequately protected from acts of theft, diversion, or sabotage.

All HEU stored in the long-term storage facility will be stored in properly designed and fabricated containers. All HEU materials stored will be in stable forms suitable for extended storage periods including:

1. Uranium metal, in the shape of

- Hollow cylinders

- Broken pieces from larger parts

- Weapon parts

2. Uranium oxide $\left(\mathrm{U}_{3} \mathrm{O}_{8}\right)$, as powder.

3. Nuclear weapon subassemblies.

Each long-term HEU storage site will perform all ancillary operations required to support its storage operations including:

- Shipping and receiving of HEU materials to and from other DOE sites.

- Packaging HEU materials in preparation for transportation or storage. 
- Performing nuclear materials control and accountability (NMC\&A) activities required to ship, receive, process, or store Category I quantities of HEU.

- Ensuring criticality-safe operations.

- Performing Health Physics monitoring.

- Sampling HEU materials.

- Controlling HEU to prevent radioactive contamination and environmental release.

- Performing chemical and isotopic analyses on HEU materials.

- Collecting waste effluents and emissions.

Each long-term HEU storage site will perform general support services including:

1. Emergency response services including

- Site security

- Fire detection and response

- Emergency medical response

- Confinement and clean-up of radioactive contamination

- Confinement and clean-up of environmental releases

2. Worker services including

- Training

- Cafeteria

- Medical

- Bioassay testing

- Labor relations

- Changehouse

- Employee benefits

3. General site services including

- Maintenance

- Engineering

- Environmental monitoring

- Industrial safety

- Industrial hygiene

- Criticality safety

- Health Physics/radiation protection

Each long-term HEU storage site will provide the site infrastructure and systems required to support storage operations including:

1. Electrical power systems and emergency back-up systems.

2. Potable water.

3. Fire water system (includes sprinklers, hydrants, and water storage). 
4. Chilled water.

5. Steam (as required).

6. Compressed air.

7. Treatment of industrial, hazardous, sanitary, and low-level waste (LLW) streams.

\subsection{Material Preparation for Long-Term Storage}

Some of the HEU material planned for the long-term storage mission exists in forms not suitable for extended storage. For example, the hydroscopic oxides $\mathrm{UO}_{2}$ and $\mathrm{UO}_{3}$ may experience weight change over time, creating material accountability problems. Highly enriched uranium currently held as oxides or other unstable compounds must be converted into the stable forms of metal or $\mathrm{U}_{3} \mathrm{O}_{8}$ oxide prior to long-term storage.

The Disposition Program assumes that all such material conversion will have been completed by the year 2020, independent of the Disposition Program. Therefore, the Disposition PEIS does not consider the environmental impacts associated with material processing and repackaging required to render all HEU suitable for extended storage.

\subsection{Other HEU-Related DP Missions}

The Disposition Program does not address all HEU operations that will continue into the future, concurrent with the long-term storage mission. The siting of these missions, and their associated environmental impact data, is beyond the scope of this report.

The following national, Defense Programs, and Disposition Program missions are among those assumed to be sited independent of the long-term HEU storage site:

1. Highly enriched uranium recovery and processing operations.

2. Highly enriched uranium manufacturing and quality evaluation operations supporting the nuclear weapons stockpile.

3. Storage of surplus HEU under IAEA safeguards.

4. Highly enriched uranium disposition operations.

5. Process and storage operations dealing with irradiated HEU materials.

6. Fabrication of HEU fuels and components (e.g., U.S. Navy).

7. Disposal of HEU mixed wastes. 


\subsection{The Y-12 Plant}

\subsection{Y-12's Current Missions}

For over 50 years, the Y-12 Plant in Oak Ridge, Tennessee, has been an integral part of the nation's Defense Programs. Within the DOE Nuclear Weapons Complex (NWC), Y-12 has long been the technological and manufacturing center for uranium and lithium materials and components. While DP missions have recently been downsized significantly, Y-12 continues to serve the nation and the DOE as a major manufacturing technology center. Current $Y-12$ Plant missions include:

- Special Nuclear Material (SNM) Warehousing and Storage.

- Work for Others on DOE-Approved Tasks.

- Technology Transfer.

- National Security Program Office.

- Environmental Restoration and Waste Management.

- Nuclear Weapons Dismantlement and Storage.

- Nuclear Weapons Production, Process Technology, and Development Support.

\subsection{Current HEU Operations at Y-12}

The Y-12 Plant performs vital HEU operations unavailable elsewhere in the United States. Its Enriched Uranium Operations (EUO) facilities recover HEU from scrap materials, purify $H E U$ from various compounds, convert $H E U$ into stable forms (e.g., hollow metal cylinders for storage), and manufacture HEU components in support of the nuclear weapon stockpile. Y-12 also disassembles nuclear weapons subsystems containing HEU and evaluates the condition of nuclear weapon subsystems containing HEU components. Y-12's Development Organization develops various $\mathrm{HEU}$ processing, manufacturing, and recovery technologies.

The Y-12 Plant currently stores HEU in several facilities, all located within the Plant's Protected Area (PA). Category I and Category II quantities of HEU (as defined in DOE Order 5633.3A, "Control and Accountability of Nuclear Materials") are stored in Material Access Areas (MAA). Within each specific MAA the HEU is stored within properly designed and built vaults or vault-type rooms.

These existing storage facilities meet or exceed current security and ES\&H regulations and requirements. The Y- 12 Plant's current storage capacity exceeds that required for the long-term HEU storage mission. 
Several tonnes of U.S. owned HEU were placed under IAEA safeguards at the Y-12 Plant in September 1994. This material was the first fissile material from nuclear weapon programs to ever be officially placed under IAEA safeguards. The Y-12 Plant was the first nuclear weapon manufacturing facility ever made available to the IAEA for safeguard and inspection purposes.

\subsection{Interim HEU Storage at the Y-12 Plant}

The DOE has evaluated the interim storage of HEU in the "Environmental Assessment (EA) for the Proposed Interim Storage of Enriched Uranium above the Maximum Historical Level at the Y-12 Plant, Oak Ridge, Tennessee." A Finding of No Significant Impact (FONSI) has been announced establishing Y-12 as the nation's repository for unirradiated HEU into the next century.

\subsection{Disposition PEIS Evaluations of the Y-12 Plant}

Under the Disposition PEIS, the Y-12 Plant HEU storage mission is being evaluated under three alternatives: the "No-Action" alternative; the "Phaseout" alternative; the "Upgrade" alternative.

"No-Action" Alternative. Under this alternative, the Y-12 Plant will continue performing its current missions past the year 2020. The long-term HEU storage mission at $Y-12$ will utilize the same facilities where HEU is currently stored, without upgrades. Contemporary operating methodologies will continue without improvement.

"Phaseout" Alternative. Under this alternative, the long-term HEU storage mission will have been removed from the Y-12 Plant by the year 2020. The balance of Y-12's missions, outside the scope of the Disposition PEIS, would continue past the year 2020 .

"Upgrade" Alternative. Under this alternative, the long-term HEU storage mission will be added to the "Phaseout" Y-12 Plant in the year 2020. By then, $Y-12$ storage facilities will have undergone the capital improvements required to ensure that all long-term HEU storage criteria are met. Likewise, storage operating methodologies will have advanced by the year 2020 .

This report provides the storage mission "Upgrade" environmental information required for the Disposition PEIS. The storage mission "No-Action" and "Phaseout" environmental data also required for the Disposition PEIS, have been provided in a separate report "No Action Alternative and Phaseout Option for Long-Term Storage of Highly Enriched Uranium at the Oak Ridge Reservation." 


\subsection{The Y-12 Upgrade Alternative}

\subsection{Long-Term HEU Storage at the Upgraded Y-12 Plant}

Under the "Upgrade" alternative, the entire HEU inventory requiring long-term storage will be stored at $Y-12$ in existing facilities; no new facilities will be built. The majority of this HEU will be housed in facilities currently utilized for HEU storage. The remaining HEU will be stored in facilities that are currently being converted into storage areas. This expansion of the plant's storage capacity is an ongoing DOE approved effort to prepare $Y-12$ for the large quantity of HEU arriving over the next few years for interim storage.

The Y-12 Plant's existing facilities that will be used for the long-term HEU storage mission include:

- Building 9204-2 First Floor MAA. Some drums are currently stored here. Ongoing conversion of floorspace within this MAA will increase its drum storage area to 18,100 square feet (sq. $\mathrm{ft}$.). (Note: all storage areas are listed in approximate values.)

- Building 9204-2E First Floor MAA. Some drums are currently stored here. Ongoing expansion of this MAA will increase its drum storage area to 9,170 sq. ft. and provide a 3,780 sq. ft. area for storing cans in Modular Storage Vaults (MSVs). The existing 3,250 sq. $\mathrm{ft}$. vault will continue storing cans.

- Building 9215 MAA. Ongoing conversion of floorspace within this MAA will provide a 17,400 sq. $\mathrm{ft}$. area for storing drums.

- Building 9998 Basement MAA. This existing 5,600 sq. ft. storage area will continue storing drums.

- Building 9212 E-Wing Vault. This existing 5,300 sq. ft. vault will continue storing cans.

Once these ongoing expansions to $Y-12$ 's HEU storage areas have been completed, these five facilities will provide more drum storage capacity than the long-term storage mission will require. Other $Y-12$ facilities that currently store HEU are not planned for use in the long-term storage mission.

The inventory of HEU going into long-term storage will be segmented into five smaller quantities, each devoted to a specific storage facility. In some cases, the quantity of HEU within a specific storage facility will be further segmented into vaults that provide separate fire protection systems.

Figure 3.1, "HEU Long-Term Storage Facilities," shows the location of Y-12's facilities that will be used for HEU long-term storage. 


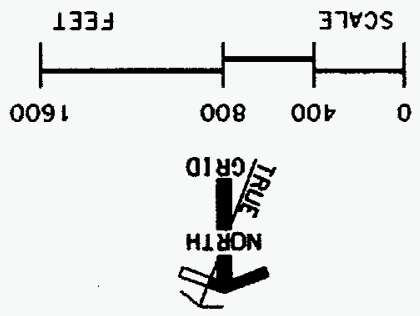

$\forall \exists y \forall$ 0 $\exists \perp J \exists \perp 0 y d$

O $\forall$ IUDddחS $\mathrm{\cap} \exists \mathrm{H} \square$

S กヨH WYIL-9NOT

$\forall \unlhd \exists O \forall Y O \perp S \quad \nabla \exists \nabla I$

0N $39 \exists 7$

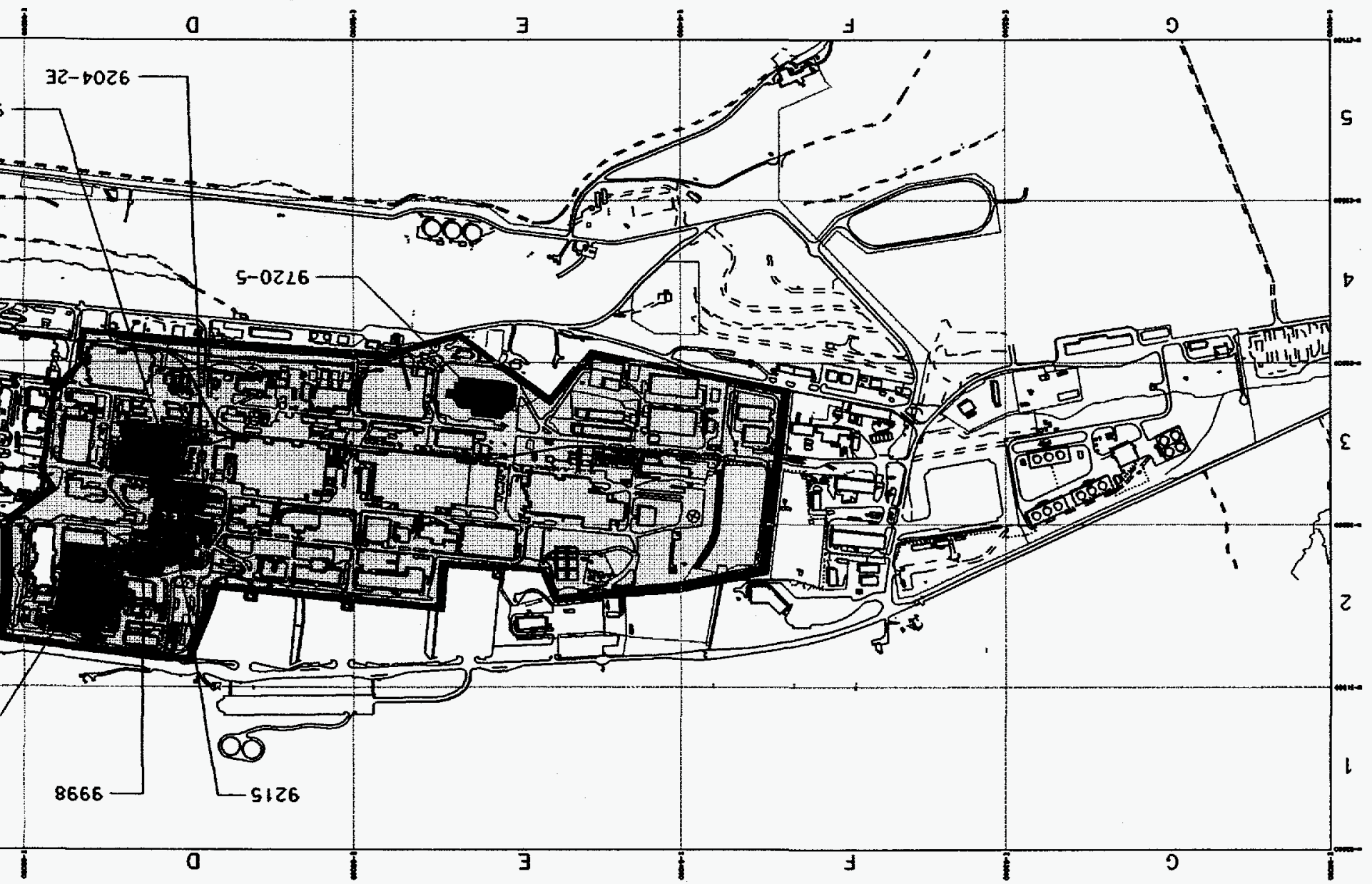

ได I

$0 \perp S$ Wy $\exists \perp-9 \mathrm{NO} 7 \cap \exists \mathrm{H}$

$\exists \circ \forall \forall \supset d \cap Z \vdash-\lambda$ 


\section{LTERNAT I VE}

\section{AGE FACILITIES}

3.1

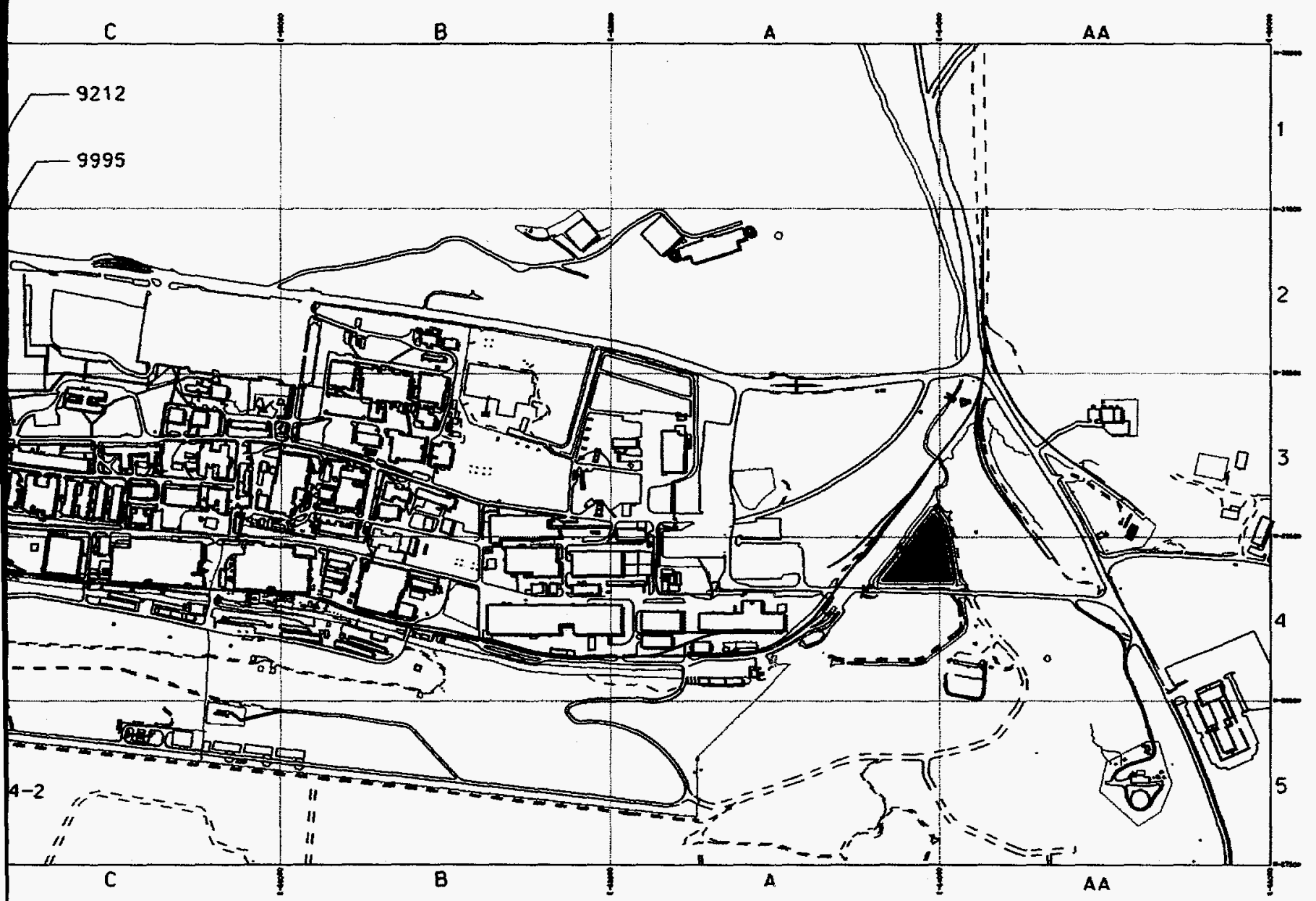

L ITY

RAGE FACILITIES

ITIES 


\subsection{Other HEU Operations in the Upgraded Y-12 Plant}

Consistent with all other scenarios being evaluated in the Disposition PEIS, the upgraded Y-12 Plant will operate past the year 2020 as a multimission site. In addition to its long-term HEU storage mission, the upgraded $Y-12$ Plant will perform other DP-related missions, some of which entail the storage and processing of HEU materials. HEU operations which are planned to operate past the year 2020 in support of these other DP missions include:

1. The recovery and purification of HEU materials. The EUO facilities, primarily housed in the Building 9212 complex, will extract HEU from various compounds to provide purified products (e.g., metal; uranium oxide). These HEU products will be stored or utilized by other DP missions.

2. The supply of HEU components in support of the nuclear weapons stockpile. Purified HEU metal will be manufactured into components needed in the active stockpile or to support the nuclear weapon design laboratories. In addition to the HEU facilities in the Building 9212 complex, existing HEU facilities in Buildings 9215 and 9998 will perform these operations.

3. The assembly and disassembly of nuclear weapon subsystems containing HEU material. Existing HEU facilities in Building 9204-2E will perform these operations.

4. The performance and quality evaluation of nuclear weapon subsystems containing HEU. Existing HEU facilities in Building 9204-2E will perform these operations.

5. The storage of any HEU remaining under IAEA safeguards beyond the year 2020. Although the Disposition Program Organization assumes that all of this material will have been dispositioned by then, Vault 16 in Building 9720-5 will remain operational as required to provide safe and secure storage of $\mathrm{HEU}$ requiring international inspection.

\subsection{Support Operations and Services}

The upgraded Y-12 Plant will perform all ancillary operations required to support its long-term storage mission. Since these ancillary operations will also support other HEU-related DP missions, they will be centralized. These ancillary operations will include:

1. Shipping and receiving HEU materials to and from other DOE sites.

2. Packaging HEU materials in preparation for transportation or storage.

3. Designing, certifying, and maintaining packages used to transport or store HEU materials.

4. Transporting HEU between plant MAAs as required. 
5. Performing NMC\&A activities required to ship, receive, process, or store Category I quantities of HEU.

6. Ensuring criticality safe operations.

7. Performing Health Physics monitoring.

8. Sampling HEU materials.

9. Controlling HEU to prevent radioactive contamination and environmental release.

10. Performing chemical and isotopic analyses on HEU materials.

11. Collecting waste effluents and emissions.

Most centralized ancillary operations will occur in the facilities where HEU operations will be performed. HEU chemical and isotopic analyses will be performed in the Plant Laboratory in Building 9995.

The Y-12 Plant will perform general support services necessary to support its long-term storage mission. Since these services will also support other HEU-related DP missions, they will be centralized. These general support services will include:

1. Emergency response services such as

- Site security

- Fire detection and response

- Emergency medical response

- Confinement and cleanup of radioactive contamination

- Confinement and cleanup of environmental releases

2. Worker services such as

- Working training

- Cafeteria services

- Medical services

- Labor relations

- Employee benefits

3. General site services such as

- Maintenance

- Engineering

- Environmental monitoring

- Safety

- Industrial hygiene

Most general support services will be located in centralized facilities. Emergency response services, maintenance, and environmental monitoring will also operate in additional facilities located throughout the plant. 
The Y-12 Plant's infrastructure will support its long-term storage mission along with other site missions. Site infrastructure will include:

1. Sitewide utility systems such as

- Electrical power, including emergency backup

- Potable water

- Process water

- Fire water system

- Chilled water

- Steam

- Compressed air

- Process chemicals (e.g., pressurized argon gas supply)

2. Treatment of industrial, hazardous, sanitary, LLW, and mixed waste streams.

3. Disposal of industrial, hazardous, sanitary, LLW, and mixed wastes.

Most of the site infrastructure will be operated in centralized facilities.

Since all ancillary operations, general support services, and site infrastructure will be required to support several Y-12 missions, the elimination of any single mission is not likely to totally eliminate any of them. Removal of a specific mission will only decrease the demand for each operation, service, or infrastructure by incremental amount, leaving the balance to support the remaining missions.

\subsection{Y-12 Upgrade}

As a site performing multiple missions, the $\mathrm{Y}-12$ Plant will undertake other capital projects between now and the year 2020. For the purpose of comparing the impact of various storage alternatives, programmatic criteria has been established for determining which capital projects should be considered as part of the Disposition PEIS. These criteria for the Y-12 upgrade are:

1. Only those capital projects that will begin after the Disposition ROD in late 1996 shall be considered in the Disposition PEIS.

2. Only those capital projects required to ensure that the long-term HEU storage mission meets programmatic requirements (e.g., full ES\&H compliance, security, capability, capacity) shall be considered in the Disposition PEIS.

3. Capital projects relating entirely to $Y-12$ missions other than the long-term HEU storage mission shall not be considered in the Disposition PEIS, regardless of their schedule.

4. The incremental portion of facility or site infrastructure upgrade projects that will be required in part because of the long-term HEU storage mission shall be considered in the Disposition PEIS. Any such upgrade project that has $25 \%$ 
or less of its total usage by the long-term HEU storage mission shall not be considered in the Disposition PEIS.

5. Capital projects required to upgrade off-site facilities (e.g., electric utility facilities) shall not be considered in the Disposition PEIS.

Only one capital project will be required for the Upgrade Alternative at the Y-12 Plant. It will ensure that all HEU storage facilities comply fully with all ES\&H requirements. That project, "Natural Phenomena Hazard (NPH) Upgrades," will improve the resistance of some storage facilities to design basis seismic events and tornadoes. More detailed information relating to this project is provided in Section 4.1.

Since the facilities planned for long-term HEU storage meet all other programmatic requirements for security and ES\&H compliance, no other upgrades will be required to them.

Because of the previously listed programmatic criteria for determining which capital projects shall be considered in the Disposition PEIS, several $Y-12$ capital projects that affect the long-term HEU storage are not included in this data report; that is,

1. The expansions to increase $Y-12$ 's storage capacity are currently under way and will not be impacted by the Disposition ROD (refer to Section 3.1). Therefore, their environmental data on these expansions are not included in this data report.

2. The incremental portion of each ancillary operation, support service, and site infrastructure that will be devoted to the long-term HEU storage mission falls below $25 \%$. Therefore, the environmental data for capital projects needed to upgrade these operations and/or facilities are not included in this data report.

3. The Disposition Program Organization assumes that all such material conversion will have been completed by the year 2020, independent of the Disposition Program. Therefore, the Disposition PEIS does not consider the environmental impacts associated with material processing and repackaging required to render all HEU suitable for extended storage. 


\subsection{Upgrade Capital Projects}

\subsection{Upgrade Capital Projects Required}

Most of the U.S. inventory of HEU is currently stored in several facilities at the Y-12 Plant. The Disposition Program is evaluating the transition of five of these facilities from their current storage missions into the long-term HEU storage mission.

These five existing facilities, as well as their ongoing storage operations, currently comply with all ES\&H and security regulations. However, one capital project is being proposed to improve the resistance of these facilities to natural phenomena events. That capital project is defined in Section 4.2.

\subsection{Natural Phenomena Hazard Upgrades}

This project will upgrade existing Y-12 storage facilities to improve their resistance to natural phenomena events such as tornadic winds and earthquakes.

\section{Technical Basis}

The following is a summary of the natural phenomena evaluations of the Y-12 Plant buildings planned for the long-term HEU storage mission. As stated above the information results were taken from Report Y/EN-5080.

\section{Building 9212 Complex (Two Structures)}

The analyses and assessments indicate that two structures used for storage require a small amount of additional cross-bracing to meet the performance goal for a moderate hazard facility or performance Category 3 facility in DOE Order 5480.28. Approximately 23 columns and 35 knee braces need to be strengthened in E-Wing. It was determined that the unreinforced masonry walls in Building 9995 had to be anchored to the structural steel frames, and the steel frames would also require additional vertical bracing. (The masonry walls in Building 9995 are not infilled in the steel frames as are the masonry walls in other evaluated buildings.) Also, some additional roof drains will be needed to provide the required secondary drainage system.

\section{Building 9204-2E}

This structure essentially meets the performance goal for a moderate hazard facility. Some additional welds of the metal roof deck to the purlins may be necessary to meet the wind load requirement.

\section{Building 9204-2}

Several modifications are required before this structure meets the performance goal. Shear walls are required between the first and second floors; seventeen beams supporting the second floor need to be strengthened, and the columns between the column lines $\mathrm{J}$ and $\mathrm{K}$ in the crane bay must be modified. 
Flooding of the first floor is possible based on the flooding information available.

\section{Building 9215/9998 Complex}

Four steel columns and two steel beams in the Penthouse require strengthening, and possibly additional welds of the steel roof deck to the purlins will be necessary.

\section{Risk Assessment}

The design and installation of the facility modifications in this project is intended to upgrade the reliability of the buildings to meet the performance goals for moderate hazard facilities. The evaluation of the identified buildings indicated required modifications to meet the performance goals. The risk level associated with the design and construction modifications for this project are considered to be low, due to the fact that the modifications are being undertaken to correct deficiencies in the facilities. The facilities are being modified to enhance the worker and environmental safety in buildings planned for the longterm HEU storage mission.

\section{Schedule}

The start of this project is not dependent on the prior completion of any other Y-12 project.

The project schedule is as follows:

Title II Design Start:

1st qtr., FY 1999

Title II Design End:

4th qtr., FY 2001

Construction Start:

1st qtr., FY 2002

Construction End:

4th qtr., FY 2004

Conceptual Design Report (CDR) activities are assumed to start two years prior to the start of Title II design. 


\subsection{Resource Needs}

\subsection{Materials/Resources Consumed for the Long-Term HEU Storage Mission}

\subsubsection{Utilities Consumed}

Table 5.1.1 shows the utilities consumed by the long-term storage mission.

Table 5.1.1. Utilities Consumed by the Long-Term Storage Mission

\begin{tabular}{|l|c|c|}
\hline \multicolumn{1}{|c|}{ Utilities } & Annual Consumption & Peak Demand \\
\hline Electricity (MWh) & 7,260 & $1.1 \mathrm{MW}$ \\
\hline Natural Gas (scf) & 33,500 & \\
\hline Coal (ton) & 180 & \\
\hline Raw Water (gal) & 63,000 & \\
\hline
\end{tabular}

\subsubsection{Chemicals Consumed}

The chemicals consumed by the long-term storage mission will be a result of the destructive analysis sampling and processing in the analytical laboratory and the bioassay analysis. Primary chemical requirements are summarized in Table 5.1.2.

These laboratories will require small amounts of other chemicals, but quantities of these are not listed because they will be less than one pound per year. 
Table 5.1.2. Annual Chemicals Consumed by the Long-Term Storage Mission

\begin{tabular}{|l|c|}
\hline \multicolumn{1}{|c|}{ Chemical } & Quantity \\
\hline \hline Hydrochloric Acid & $15 \mathrm{gal}$. \\
\hline Nitric Acid & $65 \mathrm{gal}$. \\
\hline Phosphoric Acid & $5 \mathrm{gal}$. \\
\hline Organic Solvents & $20 \mathrm{gal}$. \\
\hline Ammonium Hydroxide & $15 \mathrm{gal}$. \\
\hline Ethylene Diaminetetra & $1 \mathrm{lb}$. \\
\hline Potassium Dichromate & $1 \mathrm{lb}$. \\
\hline Ferrous Ammonium Sulfate & $1 \mathrm{lb}$. \\
\hline Sodium Hydroxide & $1 \mathrm{lb}$. \\
\hline Graphite & $1 \mathrm{lb}$. \\
\hline Resin Beads & $10 \mathrm{lbs}$. \\
\hline Uranium Oxide & $1 \mathrm{lb}$. \\
\hline Titanium Chloride & $10 \mathrm{lbs}$. \\
\hline Lithium Tetraborate & $5 \mathrm{lbs}$. \\
\hline Isopropyl Alcohol & $2 \mathrm{gal}$. \\
\hline Hydrogen Peroxide & $20 \mathrm{gal}$. \\
\hline Perchloric Acid & $2 \mathrm{gal}$. \\
\hline Sulfuric Acid & $5 \mathrm{gal}$. \\
\hline
\end{tabular}

\subsubsection{Radiological Materials Required}

Enriched Uranium will be the only radiological material handled in the upgraded HEU storage facility. Uranium Oxide will be handled in the Analytical Laboratory.

\subsection{Materials/Resources Consumed During Construction}

Table 5.2 reports the materials/resources consumed during construction to upgrade the Y-12 Plant for the long-term storage mission. 
Table 5.2 Materials/Resources Consumed During Construction

\begin{tabular}{|l|c|c|}
\hline \multicolumn{1}{|c|}{ Material Resources } & Total Consumption & Peak Demand \\
\hline \hline Electricity (MW) & & 0.1 \\
\hline Water (gal) & $0.8 \times 10^{6}$ & \\
\hline Concrete $\left(\mathrm{yd}^{3}\right.$ ) & 35 & \\
\hline Steel (ton) & 53 & \\
\hline Gasoline, Diesel Fuel, and Lube Oil (gal) & 4,200 & \\
\hline Industrial Gases & \\
\hline
\end{tabular}

${ }^{a}$ Peak demand is the maximum rate expected.

${ }^{\mathrm{b}}$ Standard Cubic Feet measured at $14.7 \mathrm{psia}$ and $60^{\circ} \mathrm{F}$. 


\subsection{Employment Needs}

6.1 Employment Needs for the Long-Term HEU Storage Mission

The incremental employment required for the long-term storage mission is summarized in Table 6.1 The labor categories used in Table 6.1 are Equal Employment Opportunity (EEO) categories.

Table 6.1. Employment for the Long-Term Upgrade Storage Mission

\begin{tabular}{||c|c|}
\hline \hline Labor Category & Number of Employees \\
\hline Officials and Managers & 14 \\
\hline Professionals & 25 \\
\hline Technicians & 16 \\
\hline Office and Clerical & 12 \\
\hline Craft Workers & 36 \\
\hline Operatives & 8 \\
\hline TOTAL EMPLOYEES & 111 \\
\hline
\end{tabular}




\subsection{Employment Needs During Construction}

Employment needs during upgrade construction are presented in Table 6.2.

Table 6.2. Number of Construction Employees Needed by Craft

\begin{tabular}{||c|c|}
\hline & Namber \\
\hline \hline Carpenter & 11 \\
\hline Concrete Mason & 1 \\
\hline Electrician & 1 \\
\hline Iron Worker & 10 \\
\hline Laborer & 10 \\
\hline Operator & 2 \\
\hline Pipefitter & 1 \\
\hline Teamster & 3 \\
\hline Other Craftworkers & 1 \\
\hline Total Craftworkers & 40 \\
\hline Construction Management and Support Staff & 10 \\
\hline Total Employment & 50 \\
\hline \multicolumn{2}{|l}{} \\
\hline
\end{tabular}




\subsection{Wastes and Emissions}

\subsection{Wastes and Emissions for the Long-Term HEU Storage Mission}

This section reports the emissions and wastes generated by activities related to the long-term storage mission.

\subsubsection{Emissions}

The emissions related to the long-term storage mission will be a result of the analytical laboratory activities required for sampling. In long-term storage facilities, destructive analysis sampling for isotopic content will only be performed occasionally. The air emissions resulting from the laboratory processing will be minimal. The total annual emissions from the long-term storage mission are shown in Table 7.1.

Table 7.1. Annual Emissions for Long-Term Storage Mission

\begin{tabular}{|l|c|}
\hline \multicolumn{1}{|c|}{ Chemical } & Quantity (1bs) \\
\hline \hline Hydrogen Chloride & 25 \\
\hline Hydrogen Fluoride & 25 \\
\hline Nitric Acid & 250 \\
\hline
\end{tabular}

\subsubsection{Solid and Liquid Waste}

The low-level waste, hazardous waste, and nonhazardous waste generated by the long-term storage mission are discussed in the subsections below. The annual quantity of solid and liquid waste generated by the storage mission is shown in Table 7.2.

\subsubsection{Low-Level Waste (LLW)}

Small amounts of low-level radioactive waste and mixed waste will be generated by long-term storage activities. Radioactive waste will consist primarily of compacted, contaminated, scrap metal or wood, samples, and vials. Mixed wastes will include waste containing both hazardous and radioactive components: such as, compacted gloves, wipes, and samples.

\subsubsection{Hazardous Waste}

Hazardous waste generated by the long-term storage mission will consist of compacted gloves, filters, rags, wipes, and chemicals. These wastes will be stabilized and sent to an approved, permitted Resource Conservation Recovery Act (RCRA) disposal site. 


\subsubsection{Nonhazardous Waste}

Nonhazardous waste (neither radioactive nor hazardous) generated by the longterm storage mission will consist primarily of trash, waste paper, packaging materials, and gloves. Nonrecyclable portions of this waste will be sent to the sanitary/industrial landfill.

Table 7.2. Annual Wastes Generated for the Long-Term Storage Mission

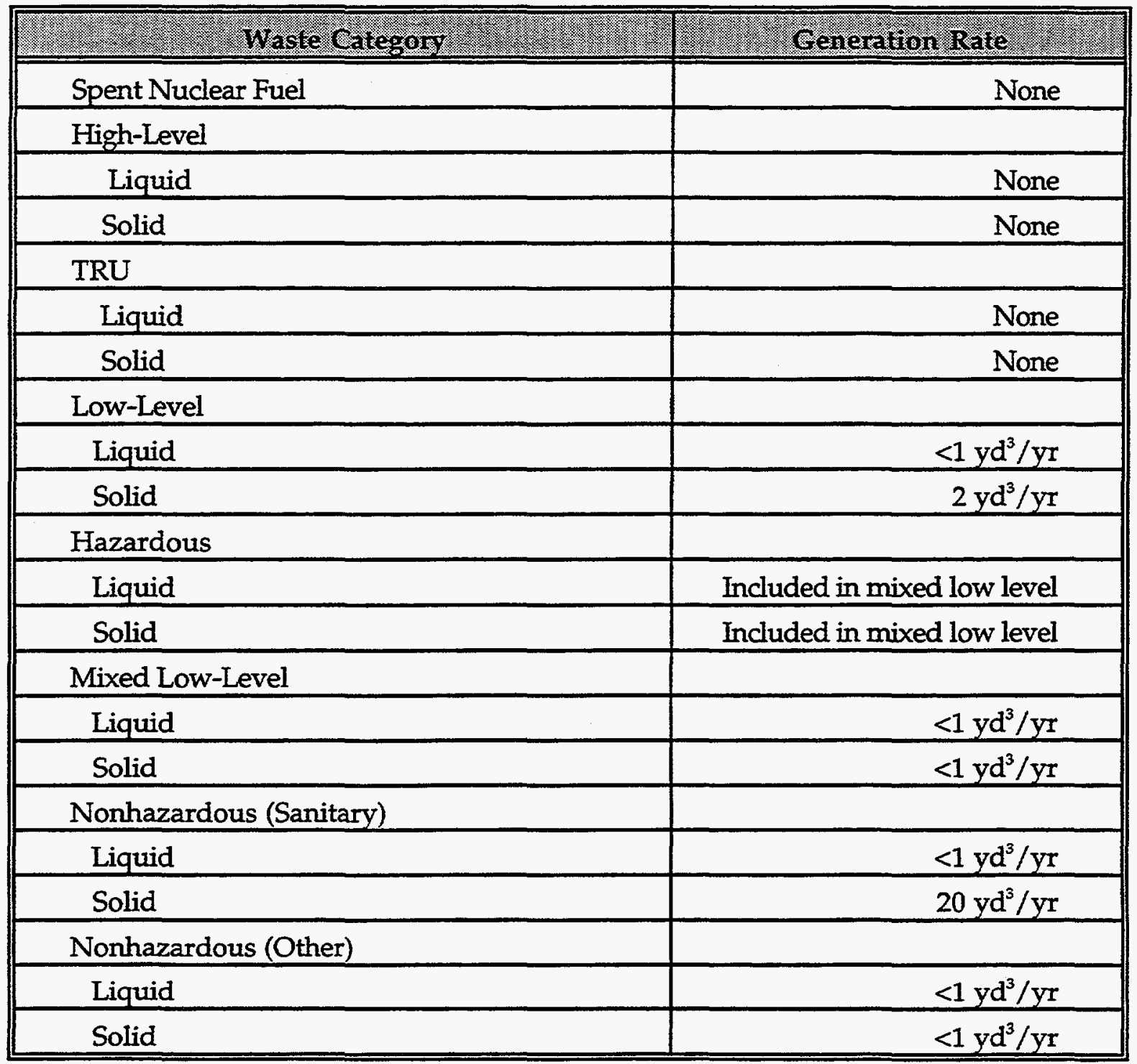

\subsection{Wastes and Emissions Generated During Construction}

This section reports the significant gaseous emissions and wastes generated during construction to upgrade the $Y-12$ Plant for the long-term storage mission. 


\subsubsection{Emissions}

The principal sources of air pollution emissions will be fugitive dust from site preparation and upgrade construction activities, as well as exhaust from construction equipment and vehicles delivering construction materials and carrying construction workers. The emissions that will be generated during the peak construction year are shown in Table 7.3.

Table 7.3. Emissions During a Peak Construction Year

\begin{tabular}{||c|c|}
\hline \multicolumn{1}{|c|}{ Chemical } & Quntity \\
\hline \hline Sulfur Dioxide & $<0.1$ \\
\hline Oxides of Nitrogen & 0.3 \\
\hline Volatile Organic Compounds & 0.4 \\
\hline Carbon Monoxide & 0.8 \\
\hline Particulate matter 10 microns and smaller & 0.2 \\
\hline Total suspended particulates & 0.3 \\
\hline
\end{tabular}

\subsubsection{Solid and Liquid Wastes}

\subsubsection{Hazardous Wastes}

There will be no hazardous wastes generated during upgrade construction.

\subsubsection{Nonhazardous Wastes}

Nonhazardous solid and liquid wastes generated during construction will include concrete and steel waste construction materials and sanitary wastewater. The steel construction waste material will be recycled as scrap material before completing construction. The total wastes generated during construction are shown in Table 7.4. 
Table 7.4. Total Wastes Generated During Construction

\begin{tabular}{||c|c|}
\hline \multicolumn{1}{|c|}{ Waste Category } & \\
\hline Nonhazardous Solids & 17 \\
\hline Concrete $\left(\mathrm{yd}^{3}\right)$ & 5 \\
\hline Steel (ton) & \\
\hline Nonhazardous Liquids & $0.8 \times 10^{6}$ \\
\hline Sanitary (gal) & 28 \\
\hline Low-level Contaminated Waste & 10 \\
\hline Concrete $\left(\mathrm{yd}^{3}\right)$ & \\
\hline Steel (ton) & \\
\hline
\end{tabular}




\section{Distribution:}

T. R. Butz

G. W. Cagle

S. O. Cox

A. I. Cygleman

R. D. Duncan, DOE-MD-3

B. G. Eddy, DOE-ORO

S. H. Howell

T. L. Hudson

J. P. Johnson

A. K. Lee, DOE-OSTI

M. A. Livesay, DOE-ORO

T. E. Magette, Tetra Tech

M. K. Morrow

I. D. Shelton

J. D. Snider

B. Stevenson, DOE-MD-4

J. D. Stout

T. H. Wynn, DOE-ORO

Y-12 Central Files

File-RC 